\title{
Behavior and properties of water in silicate melts under deep mantle conditions
}

BIJAYA B KARKI ${ }^{1}$, DIPTA B GHOSH ${ }^{1}$ AND SHUNICHIRO KARATO ${ }^{2}$

${ }^{1}$ Louisiana State University

${ }^{2}$ Yale University

Presenting Author: bbkarki@1su.edu

Water $\left(\mathrm{H}_{2} \mathrm{O}\right)$ as one of the most abundant fluids present in Earth plays crucial role in the generation and transport of magmas in the interior. Though hydrous silicate melts have been studied extensively, the experimental data are confined to relatively low pressures and the computational results are still rare. Moreover, these studies imply large differences in the way water influences the physical properties of silicate magmas, such as density and electrical conductivity. Here, we invesigate the equation of state, speciation, and transport properties of water dissolved in $\mathrm{Mg}_{1-\mathrm{x}} \mathrm{Fe}_{\mathrm{x}} \mathrm{SiO}_{3}$ and $\mathrm{Mg}_{2(1-\mathrm{x})} \mathrm{Fe}_{2 \mathrm{x}} \mathrm{SiO}_{4}$ melts (for $\mathrm{x}=0$ and 0.25 ) as well as in its bulk (pure) fluid state over the entire mantle pressure regime at 2000 to $4000 \mathrm{~K}$ using first-principles molecular dynamics. The simulation results allow us to constrain the partial molar volume of the water component in melts along with the molar volume of pure water. The predicted volume of silicate melt+water solution is negative at low pressures but becomes zero above $15 \mathrm{GPa}$ implying ideal mixing at higher pressures. Consequently, the hydrous component tends to lower the melt density to similar extent over much of the mantle pressure regime irrespective of composition. Our results also show that hydrogen diffuses fast in silicate melts and enhances the melt electrical conductivity in a way that differs from electrical conduction in the bulk water. The speciation of the water component varies considerably from the bulk water structure as well. Water is dissolved in melts mostly as hydroxyls at low pressure and as -O-H-O-, -O-H-O-H- and other extended species with increasing pressure. On the other hand, the pure water behaves as a molecular fluid below $15 \mathrm{GPa}$, gradually becoming a dissociated fluid with further compression. On the basis of modeled density and conductivity results, we suggest that partial melts containing a few percent of water may be gravitationally trapped both above and below the upper mantletransition region. Moreover, such hydrous melts can give rise to detectable electrical conductance by means of electromagnetic sounding observations. 